\title{
Literatura e Jornalismo em orquestração com a crônica no debate sobre a educação brasileira dos anos 1930
}

\author{
Literature and Journalism in orchestration with the chronicle \\ in the debate about Brazilian education from 1930 s
}

Regina Lúcia da Silva Nascimento ${ }^{1}$

http://lattes.cnpq.br/5830087042405480

Enviado em: 30/06/2018

Aceito em: 11/12/2018

\begin{abstract}
RESUMO: O objetivo deste texto é justificar a aproximação entre Literatura e Jornalismo, dois bens culturais que têm como objeto acontecimentos do cotidiano. Nesse contexto, por meio da publicação de crônicas em uma seção de jornal, Cecília Meireles, na condição de educadora e jornalista, combateu as arbitrariedades dos poderes executivo e eclesiástico relacionadas ao cenário educacional, por ocasião do Governo Provisório de Getúlio Vargas, ao defender a Escola Nova, uma teoria pedagógica alicerçada em conceitos de linhas europeia e norte-americana, as quais valorizavam os estudos realizados nos campos da Biologia, da Psicologia e da Sociologia. À luz desse tripé científico foi lançado o Manifesto dos Pioneiros da Educação Nova de 1932, no qual vinte e seis signatários, dentre eles, Cecília Meireles, defendiam a renovação educacional brasileira.
\end{abstract}

Palavras-chave: Debate. Crônica. Educação.

RÉSUMÉ: Ce texte a pour objectif de justifier la proximité entre la Littérature et le Journalisme, deux biens culturels qui ont pour objet des événements du quotidien. Dans ce contexte, au travers de la publication de chroniques dans une rubrique de journal, Cecília Meireles, en tant qu'éducatrice et journaliste, a combattu les arbitraires des pouvoirs éxécutif et ecclésiastique relationnées au scénario educationnel, pendant le Gourvernement Provisoire de Getúlio Vargas, en défendant l'École Nouvelle, une théorie pédagogique basée sur des concepts des lignes européenne et nord-américaine lequelles valorisent des études réalisées dans les champs de la Biologie, da la Psychologie et de la Sociologie. À la lumière de ce trépied scientifique a été lancé le Manifeste des Pionniers de L'Éducation Nouvelle de 1932, dans lequel vingt-six signataires, dentre eux, Cecília Meireles, défendaient le renouvellement éducationnel brésilien.

Mots-clés : Débat. Chronique. Éducation.

\section{Introdução}

É notória a participação de importantes escritores brasileiros, em páginas de jornais, ao publicarem textos sobre diversos temas ligados à realidade nacional, como, por exemplo, José de Alencar, Machado de Assis, Manuel Antônio de Almeida, Euclides da Cunha, Lima Barreto e Cecília Meireles, escritora cuja produção jornalística trouxe uma contribuição significativa para os interessados em conhecer o cenário educacional brasileiro, por ocasião do Governo Provisório de Getúlio Vargas. Nesse caso, revisitar e analisar a luta educacional da escritora supracitada é ter a oportunidade de repensar as múltiplas dimensões da

\footnotetext{
1 Doutora em Educação - (DINTER) UFU/UNIFAP. Mestre em Linguística Aplicada - (MINTER) UNICAMP/UNIFAP. Graduada em Letras Português/Francês - UFPA. Professora Associada/Curso de Letras/UNIFAP. E-mail: relusilvanas@gmail.com
} 
educação e do ensino, no tempo presente. Para tal, a leitura de crônicas de educação constitui-se como uma ferramenta importante para explorar o olhar crítico de Cecília Meireles, diante das arbitrariedades de um "ditador" possuidor de um "maquiavélico estilo político", nos dizeres da jornalista e no de Thomas Skidmore (1982), respectivamente, para assegurar e fortalecer o poder, o qual se estendeu para o campo educacional com ações que controlavam os currículos, as atividades das escolas, em nome da tão divulgada nacionalização da educação.

É importante destacar que a visão combatente de Cecília Meireles encontrou eco nas ideias de John Dewey, filósofo estadunidense que adotou a experiência, a interação, a continuidade e a democracia como categorias fundamentais para discutir a questão do conhecimento.

Cecília Meireles, como educadora interessada nessas categorias presentes no ideário da Escola Nova, movimento transformador que discutia o papel social da família, da Igreja e do Estado no âmbito da educação, lançou-se em defesa de uma renovação na esfera educacional brasileira, ao enfrentar a igreja católica e as autoridades de sua época. A esse respeito diz Valéria Lamego:

Disposta a enfrentar a Igreja, o mito da católica família brasileira, interessa-lhe a democratização do acesso ao saber, vista como atribuição do Estado [...] E não se eximirá de soltar suas farpas contra as autoridades, como o ministro Francisco Campos, Getúlio Vargas, em que condena o uso do "seu poder de ditador", ou o católico nacionalista, seguidor de Jackson de Figueiredo, Alceu Amoroso Lima. Aí aparece a riqueza deste pensamento plural de Cecília Meireles como intelectual de importância: convencida da necessidade de se inovar em educação, prefere vê-la não como possibilidade de diferentes práticas pedagógicas, mas como questão básica da cultura brasileira (LAMEGO, 1996, p. 14-15, com grifos meus).

Esse lançamento de "farpas", por meio de uma seção intitulada Página de Educação, que Cecília Meireles editava no jornal Diário de Notícias, do Rio de Janeiro no decorrer dos anos 1930, serviu como um fio condutor para organizar o artigo em torno de duas seções, nas quais ficam evidentes as bases que sustentam a intersecção entre Literatura e Jornalismo

\section{Por que a crônica?}

Compreendo que a forma pendular desse gênero em captar determinado acontecimento da vida cotidiana, em diferentes contextos, como o literário e o jornalístico, foi o aspecto que instigou Cecília Meireles a escrever "Comentários" sobre a situação educacional de sua época e vinculá-la aos seus ideais, as suas concepções de vida, de humanização, de liberdade, de arte, de formação de educando e educador, os quais foram habilmente registrados por meio de sua "veia" crítica, irônica e, em certos momentos humorística, com o intuito de trazer ao conhecimento da sociedade algumas reflexões sobre as mazelas relacionadas à questão da educação do povo brasileiro que a inquietavam e a desafiavam, como por exemplo, a coligação entre a Igreja Católica e o Governo Provisório, via pasta do Ministério da Educação.

Francisco Campos, como titular desse Ministério, por intermédio do Decreto no 19.941 de 30-04-1931, instituiu o ensino religioso nas escolas públicas do país, como matéria facultativa para os alunos, contrariando um dos princípios básicos da Escola Nova: a laicidade, aspecto que Cecília Meireles, assim como outros educadores, intelectuais e políticos defendiam, pois servia para colocar o ambiente escolar acima de crenças e disputas 
religiosas.

Entretanto, essa não era visão da Igreja, pois resgatar a importância da religião significava "reencontrar a alma nacional, o Brasil verdadeiro que, a seu ver, havia se perdido com a Constituição de 1891” (SHIROMA et al, 2007, p. 17), ao acolher princípios como o liberalismo e pregar a separação entre o Estado brasileiro e a Igreja católica.

Frente a esses aspectos contidos na lei, um grupo católico, sob a influência de D. Sebastião Leme, Arcebispo de Olinda, articulou-se com a finalidade de garantir a participação da Igreja Católica no processo de definição de princípios educacionais do povo brasileiro, uma vez que:

Para a Igreja, a educação moral do povo brasileiro deveria ser de sua exclusiva competência. Tratava-se, para os católicos, de um esforço político, patriota, uma vez que colaborando para a pureza dos costumes, estaria formando homens úteis e conscientes, com os conhecimentos necessários aos bons cidadãos. Esse projeto, conservador e tradicionalista, mas muito bem articulado por seus defensores, se desdobrou nos anos 1930 (SHIROMA et al, 2007, p. 18).

Desse modo, pressionado pelo conservadorismo da Igreja católica, o ministro Francisco Campos, político que um dia pareceu ser adepto da escola moderna, quando exerceu a função de diretor de Instrução de Minas Gerais em 1927, assinou o decreto, anteriormente citado, o qual contrariou os propósitos da Revolução de 1930 que derrubou o presidente Washington Luiz e levou ao poder Getúlio Vargas, ao considerar "as preocupações interesseiras, em lugar de se ter elevado à altura do cargo que a Revolução criou e que, para qualquer pessoa inteligente, é o mais importante e urgente nos tempos novos do Brasil" (MEIRELES, 2001, p. 45).

Por esse motivo, o referido Ministro demonstrou não entender nada de educação, pois "a sua pedagogia é uma pedagogia de ministro, isto é, politicagem...", argumentou Cecília Meireles na crônica Pedagogia de Ministro publicada no Diário de Notícias, em 30.04.1931.

Assim, o "decreto antipedagógico e antissocial" provocou um debate violento entre a Igreja e os educadores liberais que defendiam princípios básicos da Escola Nova que tanto causavam temor a um grupo de católicos: uma escola pública, laica e gratuita, enfim moderna, em que a coeducação seria capaz de contribuir para a formação de cidadãos, de ambos os sexos.

Na luta por esses princípios, a "militância jornalística” de Cecília Meireles ganhou fôlego por meio do estilo hibrido da crônica, haja vista a educadora não perder de vista o acontecimento "que lhe serve de motivo e acicate" e por isso, "não se perde em devaneios", em seus textos, os quais, provavelmente, desencadearam reflexões, comentários, críticas do leitor acerca de o cenário político e social, no qual estava inserido.

Tal pensamento ancora-se também em Angélica Soares (2005), ao situar a crônica como um gênero que está ligada ao tempo (chrónos), ou melhor, ao seu tempo porque:

o atravessa por ser um registro poético e muitas vezes irônico, através do que se capta o imaginário coletivo em suas manifestações cotidianas. Polimórfica, ela se utiliza afetivamente do diálogo, do monólogo, da alegoria, da confissão, da entrevista, do verso, da resenha, de personalidades reais, de personagens fictícias... afastando-se sempre da mera reprodução de fatos. E enquanto literatura, ela capta poeticamente o instante, perenizando-o (SOARES, 2005, p. 64).

A meu ver, foi justamente a pluralidade da crônica aliada ao poético, ao perene que sustentaram a produção de Cecília Meireles em uma coluna de jornal, durante três anos, a 
qual funcionou como uma espécie de porta-voz, dentro de um terreno de lutas acirradas em torno da educação brasileira. Tal atitude, sem dúvida, concorreu para a aproximação entre Literatura e Jornalismo, conforme defendido neste artigo.

\section{Literatura e Jornalismo na "conquista dos corações e mentes"}

Para discutir a junção entre Literatura e Jornalismo, Felipe Pena (2013) abordou uma categoria muito importante: a classificação dos gêneros, sob o ponto de vista diacrônico, ou seja, da Antiguidade Clássica ao século XX, portanto de Platão e Aristóteles a teóricos modernos, como Mikhail Bakhtin e Tzvetan Todorov.

No percurso histórico situado por Pena (2013), convém frisar que foi no começo do século XX, que estudiosos localizaram a relevância da linguagem, na conceituação de gênero. Desse modo, categorias como a diversidade e a condição discursiva ${ }^{2}$ foram levadas em conta em seus estudos. Assim, a análise sobre a questão de gênero passou a considerar a relatividade, a transformação e a transitoriedade.

Mediante esses aspectos, Pena (2013) conectou os discursos literário e jornalístico, por meio de uma aproximação conceitual, de acordo com o contexto histórico. Dessa maneira, surgiu o Jornalismo Literário definido pelo pesquisador "como linguagem musical de transformação [...], atitude narrativa em que ambos estão misturados". Logo, na compreensão do autor, "Não se trata nem de Jornalismo, nem de Literatura, mas sim de melodia (PENA, 2013, p. 21). Portanto, uma orquestração, no meu entendimento.

Para compreender, as inferências do autor em questão, é importante destacar alguns apontamentos que ele escreveu no capítulo intitulado A Literatura na história do Jornalismo, a fim de situar a trajetória do Jornalismo: origem, ligação com a história e classificação, sob o ponto de vista de diferentes pesquisadores.

Dentre as abordagens presentes na análise histórica de Pena, a de Ciro Marcondes Filho (2000), interessa sobremaneira à tessitura deste artigo, pelo fato de este autor situar a influência da Literatura na imprensa, num quadro em que ressaltou aspectos importantes como: a presença de uma produção caracterizada pelo conteúdo literário e político, sob o comando de escritores, políticos e intelectuais; a presença da chamada imprensa de massa, a profissionalização dos jornalistas, a criação de reportagens e manchetes, a utilização da publicidade e a consolidação da economia de empresa, dentre outros.

Essas colocações somadas às outras evidenciadas, ao longo do texto, concorreram para classificar a produção cronística de Cecília Meireles como uma face do Jornalismo Literário, haja vista o conteúdo literário e político em suas abordagens via imprensa conseguirem ultrapassar os limites de seu tempo, ao "captar poeticamente" determinados assuntos, os quais continuam presentes nas discussões acadêmicas e nas políticas educacionais contemporâneas, graças ao rompimento com a efemeridade, o qual garantiu "perenidade e profundidade" a sua palavra, uma vez que:

A escrita inquieta de Cecília Meireles contribuiu para a fabricação de uma nova sensibilidade pela infância, para a construção de uma nova cultura pedagógica e para a mudança de mentalidade na condução dos destinos da educação brasileira. Deixou, assim, aos leitores de ontem e de hoje, a possibilidade de se apropriar desses textos e inventar novos significados para a sua presença no movimento de renovação educacional (MIGNOT, 2001, p. 168).

${ }^{2}$ Expressão essa encontrada, inclusive, em Bakhtin (2003 [192-3/1979]). 
Ao fazer parte do grupo de leitores de hoje, na condição de educadora e de pesquisadora, ao apropriar-me de cônicas de educação de Cecília Meireles, compreendi a importância da palavra "pioneiro" em sua trajetória como signatária de o "Manifesto da nova educação ao governo e ao povo", publicado em 19 de março de 1932, o qual serviu de bandeira para travar uma luta no terreno político/educacional contra forças poderosas como Getulio Vargas e a Igreja católica.

Com essa atitude, Cecília Meireles rompeu distâncias, mobilizou e conquistou a opinião pública, por que não dizer "corações e mentes" por meio da imprensa, graças ao papel desempenhado pelas "suas crônicas finas e mordazes" publicadas na Página de Educação, em que "Notas oficiais e anúncios [...] serviram de mote, direta ou indiretamente, para seus comentários" (MIGNOT, 2001, p. 156), sobre valores como: o respeito e a solidariedade entre as pessoas, no convívio social.

Felipe Pena, apesar de o hiato cronológico que o separa de Cecília Meireles, agiu de maneira similar, quando se reportou à função do jornalista comprometido com a sociedade que busca no Jornalismo Literário, uma alternativa para honrar a profissão que escolheu em nome de causas da coletividade e não do consumismo pautado em audiência e patrocinadores. Ao agir dessa maneira, o jornalista literário tem como propósito:

Ultrapassar os limites dos acontecimentos cotidianos, proporcionar visões amplas da realidade, exercer plenamente a cidadania [...] e, principalmente, garantir perenidade e profundidade aos relatos. No dia seguinte, o texto deve servir para algo mais do que simplesmente embrulhar o peixe na feira (PENA, 2013, p. 13).

As crônicas de educação publicadas no jornal por Cecília Meireles, foram além do "embrulhar peixe na feira", uma vez que ela soube contextualizar os acontecimentos ocorridos à época, com o intuito de contribuir para a formação do cidadão, pois "a imprensa registra, comenta e participa da história. Através dela se trava uma constante batalha pela conquista dos corações e mentes" (CAPELATO, 1988, p. 13).

Nesse sentido, justamente por acreditar na potência da imprensa, Cecília Meireles não hesitou em lançar mão desse instrumento como um meio de divulgar a sua responsabilidade política frente à educação calcada em novos ideais pedagógicos e sociais, pois

$\mathrm{Na}$ vida moderna, o jornal tende, cada vez mais, a ser, para o povo, a forma rápida e imediata de cultura, e, como tal, a determinar-lhe uma orientação e a modelar-lhe um caráter.

[...] O jornal substituiu a biblioteca. Até na escola se verifica a vantagem de fazer a criança ler o que de mais interessante vai acontecendo pela terra, dia a dia, pondo-a desde logo em comunicação com fatos vivos, em vez de lhe transmitir a ciência dos livros muitas vezes já em atraso. Temos necessidade de estar ao corrente de tantas coisas que o noticiário sucinto do jornal é a súmula indispensável para estarmos a par da atualidade.

Mas, como sempre sucede, por isso mesmo que o jornal sobe de importância, como órgão informativo, sua responsabilidade cresce também, proporcionalmente, pois é mister que seja o mais verídico possível, para que não conduza ao erro o povo que se orienta pela sua leitura (MEIRELES, 2001, p. 169).

Sob essa concepção, é possível dizer que a projeção das ideias de Cecília Meireles deuse graças à maestria, à destreza com que tratava a linguagem, nos seus discursos políticos, com objetivo de instigar o leitor a uma reflexão mais profunda sobre o momento em que a educação assumia feições opressora e massificadora no Brasil. Em vista disso,

Defendia posições coerentes com a ideia universal de democracia, num período em que a

https://periodicos.unifap.br/index.php/letras

Macapá, v. 8, n. 3, $2^{\circ}$ sem., 2018 
incoerência e as paixões pelo autoritarismo arrastaram intelectuais, que levaram décadas para se reerguer do descompasso juvenil. Jornalista liberal, era defensora incansável das liberdades individuais, da paz e da instauração de uma república democrática, bem diferente daquela regida pelo populismo autoritário do regime que se descortinava (LAMEGO, 2007, p. 218).

Assim, cabe à linguagem o papel de estabelecer a relação homem-mundo, uma vez que de posse da palavra, o homem interfere no mundo. Nesse caso, "a palavra é a arma que o homem possui para dominar o mundo e fazer-se senhor dele" (FAZENDA, 2007, p. 54). Nessa direção, a habilidade de Cecília Meireles com as palavras serviu para estabelecer o seu encontro com o público e, para isso o jornal foi não só um instrumento, mas, sobretudo, um espaço fundamental.

No que diz respeito a essa interlocução, Ivani Fazenda (2007, p. 56) afirma que "através da leitura existe a possibilidade de um autêntico diálogo, pois nela não existem os entraves do relacionamento pessoa-pessoa". Desse modo, na compreensão da autora, a leitura possibilita um melhor conhecimento do mundo e de si mesmo, em virtude de a palavra só possuir sentido na ação.

$\mathrm{Na}$ minha forma de entender, o Jornalismo Literário não ignora esse fator, tanto é que, o professor Albert Chillón, da Universidade Autônoma de Barcelona, citado por Pena (2013, p. 21), diz que estamos sempre "empalavrando" o mundo". Essa visão reafirma a importância da trajetória de Cecília Meireles no contexto da imprensa nacional, pois

É fascinante ler a história do Brasil através dos jornais. Em cada página nos deparamos com aspectos significativos da vida de nossos antecessores, que permitem recuperar suas lutas, ideias, compromissos e interesses (CAPELATO, 1988, p. 13).

Tudo isso graças às relações estabelecidas entre linguagem e conteúdo habilmente veiculados nos jornais, não somente por Cecília Meireles, mas por todos os escritores de prestígio citados na Introdução deste texto, que desde a utilização do folhetim, contribuíram para o que hoje, Pena (2013), designa de Jornalismo Literário.

\section{Considerações Finais}

Nos anos 1930, houve a disputa entre as reformas empreendidas, de um lado, pelo Governo Provisório, a exemplo, as Reformas de Francisco Campos, o primeiro titular do Ministério da Educação e Saúde Pública que, em meio as suas medidas educacionais, decretou o ensino religioso nas escolas oficiais em atendimento à reinvindicação da Igreja Catolica e, do outro lado, um grupo de intelectuais que defendia a gratuidade, a obrigatoriedade, a laicidade e a coeducação, princípios de uma nova política de educação para o Brasil.

Cecília Meireles, integrante desse grupo influenciado pelo escolanovismo, foi porta voz desse ideal, por meio da imprensa, com o intuito de garantir uma escola pública e de qualidade, capaz de outorgar uma vida digna a todo povo brasileiro.

Assim, pelas mãos dessa educadora, a palavra ganhou uma força marcante nas crônicas publicadas na seção intitulada Página de Educação, do jornal carioca Diário de Notícias, com o propósito de firmar o seu compromisso com as perspectivas de mudanças na sociedade, principalmente nos campos da política educacional e da cultural do Brasil.

Por isso, ler crônicas de educação publicadas por Cecília Meireles, sob a perspectiva do Jornalismo Literário é reconhecer a importância dessa jovem educadora/jornalista, no contexto da história da educação brasileira, quando teve a coragem de enfrentar os poderes 
governamental e eclesiástico, nos anos 1930, ao tratar a educação como um problema de ordem social.

\section{Referências}

CAPELATO, Maria Helena Rolim. Imprensa e história do Brasil. São Paulo: Contexto/EDUSP, 1988.

FAZENDA, Ivani Catarina Arantes. Interdisciplinaridade: história, teoria e pesquisa. 14 ed. Campinas: Papirus, 2007.

LAMEGO, Valéria. A farpa na lira: Cecília Meireles na revolução de 30. Rio de Janeiro: Record, 1996.

. A combatente: educação e jornalismo. In: Gouvêa, Leila V. B. (Org.). Ensaios sobre Cecília Meireles. São Paulo: Humanitas, 2007, p. 217-226.

MARRACH, Sonia Alem. Cecília meireles: uma cronista da educação de uma época de mudanças. Educação em Revista, n. 3, p. 79-88, 2002.

MEIRELES, Cecília. A responsabilidade da imprensa. In: AZEVEDO FILHO, Leodegário A. Crônicas de educação, v. 4. Rio de Janeiro: Nova Fronteira; Fundação Biblioteca Nacional, 2001, p. 169.

. Epílogo. In: AZEVEDO FILHO, Leodegário A. Crônicas de educação, v. 3. Rio de Janeiro: Nova Fronteira; Fundação Biblioteca Nacional, 2001, p. 45.

MIGNOT, Ana Crhystina Venancio. Antes da despedida: editando um debate. In: NEVES, Margarida de Souza; LÔBO, Yolanda Lima; MIGNOT, Ana Chrystina Venancio.

(Org.). Cecília Meireles: a poética da educação. Rio de Janeiro: Ed. PUC-Rio, Loyola, 2001, p.149-171.

PENA, Felipe. Jornalismo literário. 2 ed. São Paulo: Contexto, 2013.

SHIROMA, Eneida Oto et. al. Política educacional. 4 ed. Rio de Janeiro: Lamparina, 2007.

SKIDMORE, Thomas. Brasil: de Getúlio Vargas a Castelo Branco. Trad. Ismênia Tunes Dantas. 7. ed. Rio de Janeiro: Paz e Terra, 1982.

SOARES, Angélica. Gêneros literários. 6 ed. São Paulo: Ática, 2005. 